OPEN ACCESS

Edited by:

Hervé Claustre,

Centre National de la Recherche Scientifique (CNRS), France

Reviewed by:

Nicholas J. Bax,

Commonwealth Scientific

and Industrial Research Organization

(CSIRO), Australia

Ward Appeltans,

United Nations Educational, Scientific and Cultural Organization, Belgium

*Correspondence:

Martina Zilioli

zilioli.m@irea.cnr.it

Specialty section:

This article was submitted to

Ocean Observation,

a section of the journal

Frontiers in Marine Science

Received: 24 December 2020

Accepted: 26 July 2021

Published: 25 August 2021

Citation:

Zilioli M, Bergami C, Carrara P, Fugazza C, Oggioni A, Pugnetti A and Tagliolato Acquaviva d'Aragona $P$

(2021) Enabling the Reuse

of Long-Term Marine Biological

Observations in Essential Variables

Frameworks Through

a Practical Approach.

Front. Mar. Sci. 8:645997.

doi: 10.3389/fmars.2021.645997

\section{Enabling the Reuse of Long-Term Marine Biological Observations in Essential Variables Frameworks Through a Practical Approach}

\author{
Martina Zilioli ${ }^{*}$, Caterina Bergami ${ }^{2}$, Paola Carrara ${ }^{1}$, Cristiano Fugazza ${ }^{1}$, \\ Alessandro Oggioni' ${ }^{1}$ Alessandra Pugnetti ${ }^{3}$ and Paolo Tagliolato Acquaviva d'Aragona ${ }^{1}$ \\ 1 Institute for Electromagnetic Sensing of the Environment (IREA), National Research Council of Italy (CNR), Milan, Italy, \\ ${ }^{2}$ Institute of Marine Sciences (ISMAR), National Research Council of Italy (CNR), Bologna, Italy, ${ }^{3}$ Institute of Marine Sciences \\ (ISMAR), National Research Council of Italy (CNR), Venice, Italy
}

Essential Biodiversity Variables (EBVs) and Biological and Ecosystem Essential Ocean Variables (BioEco EOVs) are two cooperative conceptual frameworks which help harmonize and process multi-source marine biodiversity observations into robust indexes, in order to measure progress toward policy conservation goals. Long-term monitoring networks are encouraged to contribute to these frameworks by mobilizing historical times series which are suitable for detecting impacts of management policies. In this paper, we identify specific recommendations for increasing reuse in the EV frameworks of the biodiversity historical data collected and maintained by the Gulf of Venice (GOV) site, i.e., the monitoring facility that is selected as case study in the Italian Long-Term Ecological Research network (LTER-Italy). The recommendations are obtained through a practical approach comprising two phases. In the first phase, a literature review helps extract the guidelines for implementing the principles representing the most recent attempt to unify management of EBV and BioEco EOV data, i.e., Benson's tenets. In the second phase, we compare the guidelines to the data management practices enacted by the selected monitoring site in order to recommend curation interventions. The outputs of the analysis are discussed in order to verify if the approach and the recommendations are general enough to be replicated in the marine component of monitoring networks to coordinate the LTER data contribution to the EV frameworks.

\section{Keywords: marine biodiviersity observation, global data synthesis, data management, essential variables, Long- Term Ecological Research, research infrastructure}

\section{INTRODUCTION}

Life in the oceans provides mankind with a wide range of vital benefits and resources and its protection and study are also among the United Nation Sustainable Development Goals [UN SDG 14 "Life below water" (Biermann et al., 2017)]. In order to capture the significant drivers of marine biodiversity change, which operate at multiple temporal and spatial scales, biological observing programs increased since the mid-70s (Miloslavich et al., 2018), thus calling for agreement on which 
variables have to be considered to assess biodiversity status at global scale; such an agreement has been pursued by the scientific community in the last decade.

Following the example given by development of the Essential Climate Variables in the late 1990s (Bojinski et al., 2014), two conceptual frameworks have been proposed: The Essential Biodiversity Variables (EBVs) and the Biological and Ecosystem Essential Ocean Variables (BioEco EOVs). These frameworks structure data requirements for assessing progress toward national and global conservation targets and sustainability goals (Kissling et al., 2018a; Miloslavich et al., 2018).

The EBVs framework has been developed since 2013 by the Group on Earth Observations Biodiversity Observation Network (GEO BON) (Pereira et al., 2013). It groups 22 state variables in 6 main classes $^{1}$, each one representing a level of biodiversity organization (e.g., genetic, species, community, and ecosystem) along different ecosystems (marine, terrestrial and freshwaters). The EBVs are calculated from raw data and can be illustrated as a data cube (Kissling et al., 2018a), with three basic dimensions (taxonomy, time, and space) covering different species, at different points in time and different locations. For example, this framework has been endorsed (UNEP CBD, SBSTTA, 2011; UNEP CBD, COP, 2012; UNEP CBD, SBI, 2016) by the Convention on Biological Diversity (CBD) (UNEP CBD, COP , 2010) to link primary observations to the Aichi Biodiversity Targets (ABTs) (Geijzendorffer et al., 2016; Kissling et al., 2018a). Within the GEO BON, the Marine BON (MBON) has been established in 2016 to frame the EBV concept in the marine realm and to support achievement of the ABTs number 6, 10, and 11, which pertain to marine resources.

The BioEco EOVs (Lindstrom et al., 2012) have been first identified in 2015 by the Biology and Ecosystem Panel of the Global Ocean Observing System (GOOS). Their purpose is to focus observing systems on technologically feasible and policy-relevant measurements of the living components of marine ecosystems (Miloslavich et al., 2018). Twelve priority BioEco EOVs ${ }^{2}$ describe the state of biological resources of the oceans and are grouped under six functional groups and four habitats. The BioEco EOVs are calculated through a varying number of variables (i.e., sub-variables, supporting variables, and complementary variables), which are identified in the proper Specification Sheet ${ }^{3}$ maintained and periodically updated by the GOOS Biology and Ecosystems Panel.

The relationships between the EBVs and the BioEco EOVs have been conceptually illustrated by Muller-Karger et al. (2018), who affirmed that the same set of primary measurements can be used to calculate variables under each one of the two frameworks. While there is not a one-to-one relationship linking the BioEco

\footnotetext{
${ }^{1}$ EBVs classes are: Genetic Composition, Species Populations, Species Traits, Community Composition, Ecosystem Structure, Ecosystem Function.

${ }^{2}$ The agreed BioEco EOVs are: microbe biomass and diversity, phytoplankton biomass and diversity, zooplankton biomass and diversity, fish abundance and distribution, benthic invertebrate abundance and distribution, marine turtles, birds, mammal abundance and distribution, hard coral cover and composition, seagrass cover and composition, macroalgae canopy cover and composition, and mangrove cover and composition.

${ }^{3}$ https://goosocean.org/index.php?option=com_content\&view=article\&id=14\& Itemid=114. Accessed April 30, 2021.
}

EOVs and the EBVs, the EBVs can be complementary to the BioEco EOVs (Bax et al., 2019) and the latter are used to calculate multidimensional EBVs (Canonico et al., 2019).

This encourages reuse of the monitoring and experimental records collected by observing systems working from local to regional scales, though challenges still remain in assembling and then processing such data to estimate EVs. Particularly, the joint efforts of the MBON and GOOS communities have a twofold purpose: (i) to identify "recognized" methods for harmonizing collection of variables at global scale [see the advancement of activities of the Ocean Best Practices System (Canonico et al., 2019; Pearlman et al., 2019)]; and (ii) to cross-reference data regardless the methodology used so as to preserve autonomy of the investigators (Miloslavich et al., 2018).

In fact, diversity in the methodologies for collecting data implies varying issues to be addressed when assembling measurements. For example, data sources provided by citizen scientists (e.g., local monitoring communities, volunteers) or long-tail science (e.g., historical time-series of ecological data and those collected in paper archives) often lack complete documentation to enable reuse. Also, the methodologies employed by researchers are usually established in the scope of their scientific priorities. One example is the International Bottom Trawl Surveys in the Mediterranean program $\left(\right.$ MEDITS $\left.^{4}\right)$, presenting consolidated protocols for collection and management of biological data since 1994 (MEDITS Working Group, 2017) and involving many scientific organizations operating in the region. Though these fishery-independent data, providing direct estimates of fish communities (e.g., species abundance and presence) are useful to calculate biodiversity indices, the methods are not purposefully designed to fulfill EV initiatives ${ }^{5}$ and needs. Furthermore, data are stored in national $l^{6,7}$ and/or regional ${ }^{8,9}$ databases and are disseminated in aggregated form to the specific target audiences ${ }^{10}$ to avoid privacy issues (Benson et al., 2018), thus preventing primary observations to be used for automatic aggregations and statistical expansions for other scopes.

Moreover, by comparing the habits of biodiversity scientists with those of the physical oceanography community, standard (meta)data schemas and services to format and distribute data are either underexploited (Snowden et al., 2019) or not systematically employed during research and monitoring activities. This prevents easy processing and assembling of multi-source data in both the EV frameworks (Miloslavich et al., 2018; Hardisty et al., 2019a) and represents a crucial obstacle to reuse of observations captured by monitoring programs (Bax et al., 2019), particularly those outside the network of practitioners developed by MBON to implement the EVs (Canonico et al., 2019).

\footnotetext{
${ }^{4}$ https://www.sibm.it/MEDITS\%202011/principaledownload.htm

${ }^{5}$ See https://obis.org/dataset/5173de13-ca01-44e0-bb59-9b9dfda40266 as a recent project for managing MEDITS data through Ocean Biodiversity Information System (OBIS). Accessed April 30, 2021.

${ }^{6}$ https://dcf-italia.cnr.it/web/. Accessed on May 10, 2021.

${ }^{7}$ https://www.dcf-denmark.dk/. Accessed on May 10, 2021.

${ }^{8}$ https://datacollection.jrc.ec.europa.eu/. Accessed on May 10, 2021.

${ }^{9}$ https://www.ices.dk/data/Pages/default.aspx. Accessed on May 10, 2021.

${ }^{10}$ https://medbsrdb.eu/. Accessed on May 10, 2021.
} 
The European marine monitoring sites of the International Long-Term Ecological Research (ILTER network) (Mirtl et al., 2018) can contribute to coastal and ocean observation providing a broad variety of long-term ecological in situ parameters, which may fit within the EV frameworks (Haase et al., 2018; Mollenhauer et al., 2018; Muelbert et al., 2019; Zilioli et al., 2019). Nevertheless, data management plans are compliant with the priority reporting baselines of individual sites (e.g., national best practices or international programs) and are often transferred to the technological capacity of their affiliated researchers. The resulting plurality of practices and varying degree of standardization in stewarding observations during long temporal spans is the issue currently addressed in the scientific agenda of LTER-Europe, which launched coordination of site contributions for cross-site comparison and analysis. LTER-Europe is developing the eLTER-RI ${ }^{11}$ (Integrated European Long-Term Ecosystem, Critical Zone and Socio-Ecological Research Infrastructure ${ }^{12}$ ), which specifically envisages advancement in disclosure and integration of data across different European LTER networks as well as the establishment of multilateral interactions among external initiatives and different RIs [e.g., Copernicus $^{13}$, the Integrated Carbon Observation System $\left(\mathrm{ICOS}^{14}\right)$, European Research Infrastructure Consortium $\left(\right.$ ERIC $\left.^{15}\right)$, LifeWatch ${ }^{16}$ ERIC, the International Co-operative Program on Assessment and Monitoring of Air Pollution Effects on Forests (ICP Forests ${ }^{17}$ )]. With respect to this, the ongoing provision of the available biodiversity time-series is organized through specific data calls ${ }^{18}$ which are involving various research groups in updating the data management operations. Many specific formats cannot be easily mapped one onto the other, and reducing labor and/or training costs for preparing data produced in such a multiplicity of contexts should encourage the identification of common translating patterns. Particularly, since ILTER supports data interoperability of its regional networks with the EVs (Mirtl et al., 2018), it is useful for the LTER researchers to change their practices to also meet these requirements, with the least effort possible in data restructuring and through service enablement (Peterseil et al., 2020).

The objective of this study is to verify how the marine LTER historical time series can be reused in the EV frameworks, and to identify specific recommendations for improving their current data management through a practical approach, within the context of a specific case study.

Our approach articulates into two different phases:

\footnotetext{
${ }^{11}$ The eLTER RI s an emerging facility (Mirtl et al., 2018) which has undertaken a formalized process to be recognized as a European RI; https://www.lter-europe. net/elter-esfri.

${ }^{12}$ https://ec.europa.eu/info/research-and-innovation/strategy/europeanresearch-infrastructures_en. Accessed April 29, 2021.

${ }^{13}$ https://www.copernicus.eu/it. Accessed April 30, 2021.

${ }^{14}$ https://www.icos-cp.eu/. Accessed April 30, 2021.

${ }^{15}$ https://ec.europa.eu/info/research-and-innovation/strategy/europeanresearch-infrastructures/eric_en. Accessed April 30, 2021.

${ }^{16}$ https://www.lifewatch.eu/it. Accessed April 30, 2021.

${ }^{17}$ https://unece.org/fileadmin/DAM/env/lrtap/WorkingGroups/wge/forests.htm. Accessed April 30, 2021.

${ }^{18} \mathrm{https}$ //www.lter-europe.net/projects/PLUS/call-for-ecosystem-andbiodiversity-data. Accessed April 26, 2021.
}

The first phase focuses on the tenets described in Benson et al. (2018); these are five principles which represent the most recent attempt to unifying management of EBV and BioEco EOV data and to foster adoption of an integrated operational setting among experts who sample biological components. In this phase, a literature review will help us extract a set of guidelines to implement Benson's tenets. In doing this, we highlight common aspects and coordination efforts between the two frameworks as well as the open issues to be addressed by further works and projects.

In the second phase, we match the identified guidelines against the current data management practices enacted by a specific marine research and monitoring site in the Italian LTER network (LTER-Italy) ${ }^{19}$, which is selected as a case study. LTER-Italy hosts the highest numbers of LTER coastal and transitional waters sites in LTER-Europe: These are 19, grouped into eight parent sites, according to geographical proximity and ecosystem typology. We focus on the Gulf of Venice (GOV) site in the Northern Adriatic Sea, whose research staff has recently allocated workforce and technological resources to improve management of the time series collected since 1965 (Acri et al., 2020). The GOV's 50-year dataset (19652015), containing 21 biotic and abiotic parameters, allows for testing and assessing compliance of the site data management practices with the EV guidelines. On this basis, we then propose a set of recommendations to improve storage, handling, and preservation of the measurements collected by the GOV site to increase compliance with both the EV frameworks.

Finally, we discuss prospective application of the proposed approach in other LTER marine sites. This could stimulate coordination in data management among sites at national- as well as at the eLTER RI- and ILTER-level for consistent contribution to a global and interconnected research environment.

\section{MATERIALS AND METHODS}

\section{Phase 1: Identification of the Guidelines for Implementation of the Key Tenets}

The core of this phase is represented by the tenets described in Benson et al. (2018). The tenets, proposed in the context of the collaboration agreement between the GOOS, the Ocean Biodiversity Information System (OBIS), and MBON, are reported in the following:

1 Standardized data collection: Recommends that data for a minimum set of essential variables (EBVs/BioEco EOVs) are collected using comparable methods across time and sites;

2 Addressing global reporting needs: Recommends to consider both national regulations and global policy reporting requirements when producing outputs through modeling efforts or conducting monitoring activities;

\footnotetext{
${ }^{19} \mathrm{http}: / /$ www.lteritalia.it. Accessed April 29, 2021.
} 
3 Making data FAIR: Recommends to comply with the FAIR Principles $^{20}$ (Findability, Accessibility, Interoperability, and Reusability);

4 Analytical algorithms, tools, and workflow are accessible: Recommends sharing of analytical algorithms, workflows, and provenance information of the data to assure reproducibility of the experiments;

5 Adhering to the Action Ecology principles: Recommends to apply the Action Ecology principles ${ }^{21}$ to all parts of the system to provide policy-ready suggestions.

The approach we followed to outline the guidelines needed to address the tenets is to explore and examine the academic literature and to elaborate on the guidelines from the selected papers. To this purpose, the BioEco EOVs and EBVs-related literature (i.e., peer-reviewed papers, technical reports, and online documents) was searched and analyzed; in Figure 1 we illustrate the five tenets and the questions we formulated to perform this task. The guidelines, i.e., the output of Phase 1, are summarized in a synoptic comparison matrix which will be presented in section "Results." As we aim at testing promptly reuse of marine biological measures, we take into consideration tenets $1-4$, and we assess compliance with tenets 1 and 2 to achieve the policyrelevance discussed by tenet 5 .

\section{Phase 2: Information Sources Selected for Documenting Data Collection and Management in the Gulf of Venice}

As anticipated in the Introduction, we select as case study the GOV, which is one of the LTER-Italy marine research sites. In the GOV site, meteo-oceanographic and biological data are gathered both at a fixed point observing system [i.e., Acqua Alta Oceanographic tower (Ravaioli et al., 2016)] and during oceanographic cruises. The selection of the GOV was driven by its different features, relevant to our aims. First of all, the GOV enacted a long-term measurement program of biological components, which is pre-requisite for all sites of the LTER networks. Second, it developed the Open Science (OS) initiative named "EcoNAOS" (Ecological Northern Adriatic Open-science Observatory System), where OS principles have been applied to the long-term ecological data gathered in 50 years in this area (Minelli et al., 2018, 2021; Acri et al., 2020). Third, the GOV is involved in the design and implementation of a marine ecological observatory in the Adriatic Sea. The observatory deployment is carried out within the Interreg V-A Italy-Croatia project ECOSS ${ }^{22}$ (ECOlogical observing System in the Adriatic Sea: oceanographic observations for Biodiversity), which aims at integrating ecological and oceanographic research

\footnotetext{
${ }^{20}$ https://www.force11.org/group/fairgroup/fairprinciples. Accessed April 29, 2021.

${ }^{21}$ Action Ecology is defined as the research explicitly targeted at providing relatively fast but effective analyses of diversely scaled and multifaceted datasets to inform policy and support decision-making about on-going ecological problems (White et al., 2015).

${ }^{22}$ https://www.italy-croatia.eu/web/ecoss/about-the-project. Accessed April 29, 2021.
}

and monitoring activities with the Natura $2000^{23}$ conservation strategies (Manea et al., 2020). The crucial aspect of this process is to link local, country-specific initiatives in order to evolve common approaches to data acquisition and management, which need to be compliant with both the EV frameworks (Benedetti-Cecchi et al., 2018; Rogers et al., 2020) and the main EU Directives.

For analysis of data management practices of the GOV, we leverage on the informative sources listed in the following. They allow us to describe the attitude and experience of the site managers and the scientific staff in handling data with respect to the EV frameworks.

- The LTER Dynamic Ecological Information Management System - Site and Dataset Registry [DEIMS-SDR ${ }^{24}$, (Wohner et al., 2019, 2020)]. DEIMS-SDR is the official site catalog of the ILTER community as well as one of the key components of the eLTER RI Information System ${ }^{25}$. It is based on a repository of the metadata for sites, sensors, datasets, and activities of the networks. It has been queried to consult both the LTER research programs (Mollenhauer et al., 2018) and the handling practices with respect to observations contributing to EBVs (Zilioli et al., 2019). The site and dataset metadata of the GOV are filtered and analyzed for the elements reported in Supplementary Tables 1, 2 according to the methodology described in Mollenhauer et al. (2018) and Zilioli et al. (2019).

- The statements of the EcoNAOS initiative. EcoNAOS is specifically designed to make management of marine ecological data compliant with the OS principles. Its six main tasks (i.e., IT development and curation activities carried out by the scientific staff to disclose the whole research lifecycle of long-term time series) represent the backbone of the initiative and are fully described and accessible in Minelli et al. $(2018,2021)$. They are:

- Task 1: Harmonization of measurements of time series

- Task 2: Rescue of available metadata

- Task 3: Integration of historical time series in an interoperable data infrastructure

- Task 4: Publication of ideas and tools for processing time series

- Task 5: Dynamic citation for time series

- Task 6: Output guidelines

- The 50-year dataset of biotic and abiotic observations described in the data paper (Acri et al., 2020). The dataset is composed of observations on physical and chemical parameters and on phytoplankton and zooplankton abundances, collected from 1965 to 2015 during several oceanographic cruises. The metadata of the dataset is described in the DEIMS-SDR and the whole dataset

\footnotetext{
${ }^{23}$ https://ec.europa.eu/environment/nature/natura2000/index_en.htm. Accessed April 29, 2021.

${ }^{24}$ https://deims.org/. Accessed April 29, 2021.

${ }^{25}$ https://data.lter-europe.net/. Accessed April 29, 2021.
} 


\section{Management of marine biological data}

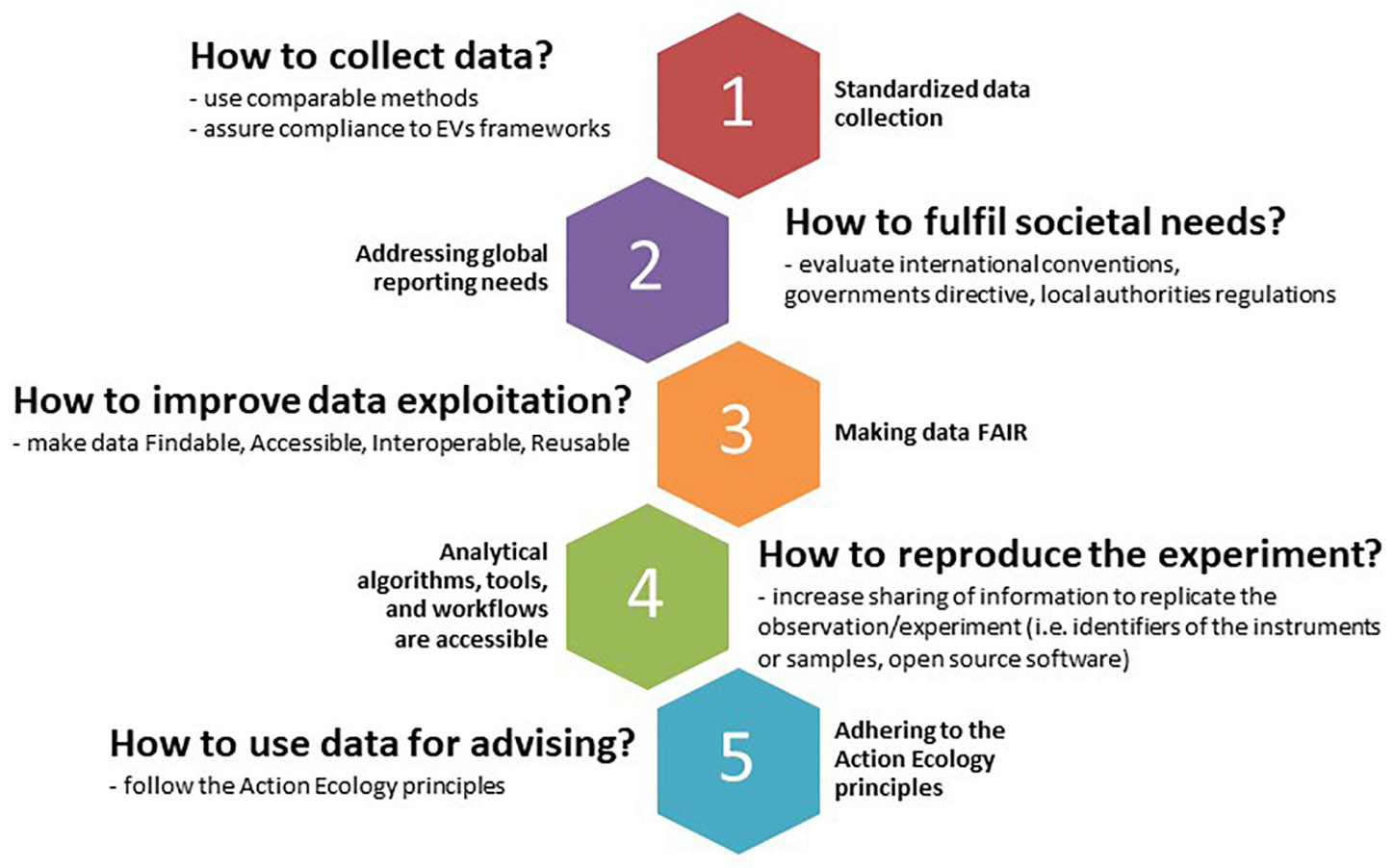

The five key-tenets (Benson et al. 2018)

FIGURE 1 | The concept of management of marine biodiversity data addressed along with the five key-tenets envisioned by Benson et al. (2018).

(Acri et al., 2019) is published in Zenodo, a public and open repository. The whole material referred to the 50 -year dataset is analyzed to extract both the observed parameters and the methods used for acquisition and analysis of data.

The output of Phase 2 is a comparison of the practices detected in the GOV with the guidelines derived in Phase 1; this result, depicted in a compliance matrix, is also presented in the section "Results."

\section{RESULTS}

\section{Phase 1. Guidelines to Meet the Tenets}

This section describes the guidelines referred to each tenet by reporting how they are derived from the literature in hand. They are classified in a synoptic comparison matrix (Table 1).

As regards tenet 1 Standardized data collection, we identify in the Technical Specification Sheets (TSSs) ${ }^{26}$ published by GOOS synthetic information on how current monitoring of the BioEco EOVs is organized around the globe. The TSSs illustrate: (i) a classification of the information needed to calculate each essential variable and the best practices for

\footnotetext{
${ }^{26}$ https://goosocean.org/index.php?option=com_content\&view=article\&id=14\& Itemid=114. Accessed April 29, 2021.
}

collecting measurements whenever available, (ii) a categorization of the observing elements (e.g., satellites, ships, autonomous platforms, and monitoring networks) to be coordinated, and (iii) the different approaches to data creation and management enacted by the existing communities. With respect to developing a standardized approach to observe or model the EOVs, we consider the TSSs as the basis for identifying the observing requirements the local monitoring program could fulfill and where its contribution is positioned with respect to the communities distributed across continents. Particularly, we identify in the TSSs the guidelines to classify the information requirements of the GOOS framework (i.e., sub-variables, supporting variables, complementary variables, and derived products) as well as the best practices and methods to refer to Table 1-row 1, column 2.

In addition to that, the GEO BON guidelines proposed in the EBV-related literature (Costello et al., 2017) suggest to explicitly recognize the biases of the method chosen (e.g., the threshold in detection) and to use appropriate thesauri and classification systems to assure comparability among different methods along the same observed feature (Table 1-row 1, column 1). Instead of assuming conventional methods, these guidelines are useful to provide the data managers with ways to address the comparison of methods across geographical and temporal scales. From these guidelines, we derive two complementary approaches, 
TABLE 1 | The synoptic comparison matrix.

\begin{tabular}{|c|c|c|}
\hline $\begin{array}{l}\text { Key-tenets (Benson et al., } \\
\text { 2018) }\end{array}$ & EBVs (Pereira et al., 2013) & BioEco EOVs (Miloslavich et al., 2018) \\
\hline 1. Standardized Data Collection & $\begin{array}{l}\text { Identify the in situ observations that contribute to the EBVs and } \\
\text { describe their taxonomic, spatial, and temporal extents; } \\
\text { explicitly recognize the biases of the method chosen and use } \\
\text { appropriate thesauri and classification systems to assure } \\
\text { comparability among different methods (Costello et al., 2017) }\end{array}$ & $\begin{array}{l}\text { Leverage on the GOOS TSSs to link in situ observations to the } \\
\text { variables required to model the BioEco EOVs (i.e., distinguish } \\
\text { among supporting, complementary, and sub-variables); } \\
\text { describe if methods vary diachronically }\end{array}$ \\
\hline $\begin{array}{l}\text { 2. Addressing Global Reporting } \\
\text { Needs }\end{array}$ & $\begin{array}{l}\text { Consider the international policy reporting requirements which } \\
\text { can be benefit from the EBVs derived from monitoring activities } \\
\text { or national data products }\left(\mathrm{CBD}^{i} \text {, Ramsar Directive, CMS }{ }^{i i} \text {, }\right. \\
\left.\text { Habitat Directive, Birds Directive, MSFD }{ }^{i i i}, \mathrm{WFD}^{i v}\right)^{v} \text {; check if the } \\
\text { stakeholders operating at national level (e.g., policy makers and } \\
\text { resource managers) are involved in monitoring projects to } \\
\text { inform decisions (Geijzendorffer et al., 2016) }\end{array}$ & $\begin{array}{l}\text { Consider the international reporting requirements which can } \\
\text { benefit from the BioEco EOVs derived from national data } \\
\text { products ( } 24 \text { global agreements); check if the stakeholders } \\
\text { operating at national level (e.g., policy makers and resource } \\
\text { managers) are involved in monitoring projects to inform } \\
\text { decisions (Miloslavich et al., 2018) }\end{array}$ \\
\hline \multirow[t]{3}{*}{ 3. Making Data FAIR } & \multicolumn{2}{|c|}{$\begin{array}{l}\text { Standardize the formats for data (e.g., Darwin Core Archive, DwC MeasurementOrFact (MoF), DwC } \\
\text { ExtendedMeasurementOrFact (eMoF), JSON) and metadata (e.g., EML, ISO19115, ISO 19157) (De Pooter et al., 2017; Kissling } \\
\text { et al., 2018a; Hardisty et al., 2019b; Snowden et al., 2019) }\end{array}$} \\
\hline & \multicolumn{2}{|c|}{$\begin{array}{c}\text { Publish data in global information systems (e.g., the Global Biodiversity Information Facility and the Ocean Biodiversity } \\
\text { Information System) to improve accessibility; these two IT facilities are based on common technologies and comply with the } \\
\text { same standards (Klein et al., 2019) }\end{array}$} \\
\hline & $\begin{array}{l}\text { Consider the Bari Manifesto principles to increase reuse of } \\
\text { monitoring data products at global level while assuring } \\
\text { autonomy of the research infrastructure or program (Hardisty } \\
\text { et al., 2019b) }\end{array}$ & $\begin{array}{l}\text { Evolve pragmatic ways (tools, actions) to bridge between the } \\
\text { data and metadata standards across science disciplines; } \\
\text { assess balance between global interoperability and the local } \\
\text { project priorities (Lindstrom et al., 2012; Snowden et al., 2019) }\end{array}$ \\
\hline $\begin{array}{l}\text { 4. Analytical Algorithms, Tools, } \\
\text { and Workflows Are Accessible }\end{array}$ & $\begin{array}{l}\text { Check if globally agreed workflows for managing and making } \\
\text { data accessible are developed around the contributed EBVs } \\
\text { (e.g., Species distribution and Population abundance global } \\
\text { data products) and assess compliance with the workflow } \\
\text { (Kissling et al., 2018a,b; Jetz et al., 2019) }\end{array}$ & $\begin{array}{l}\text { Check if workflows for managing and making data accessible } \\
\text { are proposed by a EOV regional community (e.g., EMODnet) or } \\
\text { by an observing element of GOOS (e.g., the Continuous } \\
\text { Plankton Recorder, GCRMN); assess compliance with the } \\
\text { workflow (Batten et al., 2019; Obura et al., 2019; Lear et al., } \\
\text { 2020) }\end{array}$ \\
\hline
\end{tabular}

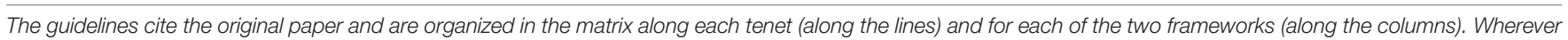

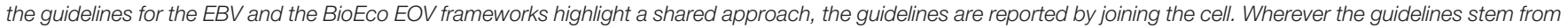
framework-specific literature, the guidelines are presented in separated cells.

'Convention on Biological Diversity;

"Convention on Migratory Species of Wild Animals;

iii Marine Strategy Framework Directive;

iv Water Framework Directive;

"According to the ENVRI Plus Reference Model data product is "an instance of persistent [meta]data which has been processed to be offered to external users".

that shall be adopted simultaneously by observing systems in contributing to $\mathrm{EV}$ programs.

As regards tenet 2 Addressing global reporting needs, we selected literature sources to identify the policy reporting conventions that can be supported by the EVs. Indeed, the EVs are conceived to be combined into indicators to evaluate progress toward objectives of international agreements and regulations (Miloslavich et al., 2018; UNEP CBD, SBI, 2016; Muller-Karger et al., 2018). This is gaining in importance after the 2020 CBD meeting (UNEP CBD, SBSTTA, 2020), which stimulated discussion on limits that prevent achievement of the ABTs (Mace et al., 2018; Phang et al., 2020; Hagerman et al., 2021; Xu et al., 2021). These limits can be bridged by taking advantage of the role of the EVs in delivering knowledge-based information (Anonymous, 2019; Hoban et al., 2020; Geldmann et al., 2021) and in assessing quality of the national and global indicators (Geijzendorffer et al., 2016; Vihervaara et al., 2017). In fact, the EVs have been employed as analytical frameworks to identify the informative gaps of indicators that impact negatively on the robustness of the latter. Specifically, in Geijzendorffer et al.
(2016) the reporting needs of seven global and European policy instruments were identified and then linked by experts to indepth knowledge of specific policy instruments to specific EBV classes. The analysis illustrates a sound method to reference the EBVs-primary data to the requirements of the global and national agreements concerning biodiversity (Table 1-row 2, column 1). In Miloslavich et al. (2018), a list of twenty-four international conventions is analyzed to cluster the drivers (i.e., the societal needs) and the pressures (i.e., anthropogenic stressors) that the BioEco EOVs can address by modeling the measurements collected at any scales (Table 1-row 2, column 2). Hence, the connections between policy reporting instruments and the BioEco EOVs are identified by design.

In these works, both the EBVs and the BioEco EOVs are linked to the $\mathrm{ABTs}$ of $\mathrm{CBD}^{27}$, to the $\mathrm{UN}-\mathrm{SDGs}^{28}$, and to distinct programs of the United Nations Environment Program

\footnotetext{
${ }^{27}$ https://www.cbd.int/sp/targets/. Accessed April 30, 2021.

${ }^{28}$ https://sdgs.un.org/goals. Accessed April 30, 2021.
} 
$(\mathrm{UNEP})^{29}$. Nevertheless, the current state of the art falls short of discussing the benefits of the BioEco EOVs monitoring program for national legislations and European Directives (e.g., the Convention on Migratory Species of Wild Animals, the Marine Strategy Framework Directive, the Water Framework Directive). It will be useful for policy makers, implementing agencies, resource managers, and scientists operating at these scales to easily cross-tabulate, through experts' validation, the BioEco EOVs and the European binding agreements, both to capitalize on the monitoring efforts and to increase reuse of data for different purposes.

In both frameworks, dialog with researchers and stakeholders is crucial to building or disseminating data products so as to implement the recommendation of tenet 2 .

As for tenet 3, Making data FAIR, we identify in the literature multiple examples of how the two EV frameworks foster the FAIR principles (Wilkinson et al., 2016) in data management, both with autonomous and coordinated initiatives.

Two informative systems are considered (Table 1-row 4) to maximize centralization of data access and distribution at global scale (Bax et al., 2019). The Global Biodiversity Information Facility (GBIF) is largely accounted (Hardisty et al., 2019a; Jetz et al., 2019) for sharing biodiversity measurements as it offers standard services to distribute the data captured by input users with various expertise along different taxa and ecosystems (marine, terrestrial, and freshwaters). Instead, OBIS is suggested (Benson et al., 2018) as a repository for registering and finding the BioEco EOVs through standard tools because of its consolidated community of users. Beside the federation function facilitated by these information systems, beyond the EV programs, their respective users and data-publishing institutions can benefit from more streamlined ways of working together. This is attested by a recent agreement ${ }^{30}$ between the two facilities, which was signed on September 1st, 2020. The collaboration envisions a number of goals, among which (i) to encourage OBIS nodes and GBIF data providers to publish marine data in both facilities using a single publishing step, and (ii) to align written guidance on publication of the data to OBIS and GBIF. Nevertheless, the IT facilities already collaborate for technology issues since (i) OBIS supported the Integrated Publish Toolkit (IPT) developed by GBIF, (ii) they are working with the same data standard, and (iii) automatic harvesting between GBIF and OBIS tier two nodes is recommended ${ }^{31}$.

Also, advancements in the direction of integrating GBIF and OBIS have been made, so that data flow between the two facilities is enabled ${ }^{32}$. This way, both can work directly with the entire marine community and promote its standards and best practices without duplication of effort.

Even though data archiving is not compulsory in the two facilities, both the EV frameworks recommend adoption of standards for metadata and data, summarized below

\footnotetext{
${ }^{29}$ https://www.unep.org/. Accessed April 30, 2021.

${ }^{30} \mathrm{https} / / /$ www.obis.org/documents/OBIS\%20GBIF\%20Letter\%20of\%

20Agreement\%20-\%20FINAL-SIGNED.pdf. Accessed April 30, 2021.

${ }^{31}$ https://obis.org/manual/nodes/. Accessed April 30, 2021.

${ }^{32}$ http://www.eurobis.org/data_flow. Accessed April 29, 2021.
}

(Table 1-row 3). This allows scientists to contribute to EV-related initiatives by exploiting individual services (i.e., organization- or institution-based information systems, repository or national databases).

Currently, providing measurements for the two frameworks implies different choices of schemas for representing data and metadata, since each variable is likely to have its own distinct data model. Accepted community standards like the Darwin Core Archive (DwC-A $)^{33}$, which is maintained by the Biodiversity Information Standards (TDWG), is suggested (Kissling et al., 2018a; Snowden et al., 2019) for representing the structure both of the EBV and BioEco EOV occurrence reports, taxon checklists, sampling events, and measurements in order to facilitate in the future more easy and automatic integration. In fact, while the DwC was initially intended to represent occurrence observations only, recent advancements allow for expanding OBIS with other types of information, suitable to fit the requirements of the marine biodiversity community (De Pooter et al., 2017). Two DwC extensions, i.e., the MeasurementOrFact (MoF) and the ExtendedMeasurementOrFact $(\mathrm{eMoF})^{34}$, serve the purpose of representing new data types and sampling facts $^{35}$ in DwC-A, overcoming the more constraining schema requirements of the original $\mathrm{DwC}^{36}$. In order not to impede representation of new schemas, these extensions allow for definition of new entities by means of simple texts (for defining both data types, values, and units), potentially weakening the DwC interoperability. To overcome this issue, and to maintain semantic interoperability of such less strict schematization, it is highly recommended the use of URIs instead of simple texts for linking measurement types, values and units to internationally acknowledged controlled vocabularies and thesauri (OBIS, 2021). Please refer to Bordogna et al. (2021) for an updated account of perspectives on semantics in geo-based information.

The Ecological Metadata Language (EML) (Jones et al., 2019) is recommended to structure metadata information for the purpose of data discovery, for interpretation of data, and for assessment of fitness-for-use. Also, other metadata schemas, such as ISO19115 (ISO TC 211, 2014), ISO19157 (ISO TC 211, 2013), and the INSPIRE Environmental Monitoring Facilities (Inspire Thematic Working Group on Environmental Monitoring, 2011; Zilioli et al., 2019) are suggested in the literature on EBVs (Kissling et al., 2018a) for the high definition of the temporal, geographical, and taxonomical information required for processing EBV datasets.

From an historical perspective, data interoperability for the EBVs and the BioEco EOVs was formulated and discussed in different documents, but it is crucial to both communities and it is developed through collaboration between the two organizations. Both frameworks deal with heterogeneity of providers and the fragmentation of the data sources. Interoperability was

\footnotetext{
${ }^{33}$ https://dwc.tdwg.org/. Accessed April 29, 2021.

${ }^{34}$ Please note that eMoF extension is only considered in OBIS and not in GBIF.

${ }^{35}$ Within eMoF, sampling facts (e.g., instrument metadata, sampling protocol, etc.) can be provided, by means of text or (as OBIS recommends) in form of URLs pointing to external documentation.

${ }^{36}$ https://obis.org/manual/dataformat/\#envdata. Accessed April 29, 2021.
} 
addressed to increase reuse of data by assuring scientific autonomy of providers.

At present, the EBVs and the BioEco EOVs share no prescriptive methods for management of the related data but some features to reach interoperability are essential to allow exchange of information when the individual components (i.e., the data service used by providers) are different and maintained by separate organizations.

The Bari Manifesto (Hardisty et al., 2019b) is the interoperability framework proposed for the EBVs. It encapsulates ten principles agreed upon by the representatives of biodiversity IT facilities and it outlines the current best practices in EBV-related informatics. These principles are related to data management topics (e.g., plans, metadata, workflows, ontologies/vocabularies, provenance, structure, quality, services, preservation, and accessibility of data) and provide guidance on how to achieve EBV estimation through trans-national and crossinfrastructure workflows in a computer assisted environment. We suggest these guidelines (Table 1 -row 5, column 1) to be followed by the observing elements that belong to research infrastructures (e.g., the eLTER RI) or monitoring networks. Analogously, the Framework for Ocean Observing ${ }^{37}$ (FOO) (Kissling et al., 2018a), rather than being organized around specific observing platforms, programs, or regions, is organized around the EOVs that are fed by several observing elements. In the analysis led by Snowden et al. (2019), interoperability among the elements of the GOOS promoted in the FOO (Miloslavich et al., 2019) is further evolved. Snowden et al. (2019) present a set of guidelines (Table 1-row 5, column 5) and considerations for each of the research domains involved in the FOO. Compared to physical and chemical oceanography, the biodiversity community demonstrates both a slower adoption of standards and difficulties related to the use of standards developed for other disciplines (particularly, the Earth science/geospatial standards). Moreover, integration of data from closely related communities (biodiversity and ecology) might be hindered by the use of different metadata models with a few common elements. The authors stress the crucial role of the Information management community in developing tools to reach compliance of data with well-established interoperability data standards. They also stress the importance of mapping the individual schemas to facilitate semantic reconciliation of attributes between the (meta)data produced by the communities involved.

As regards tenet 4 Analytical algorithms, tools, and workflow are accessible, we focus on works that describe approaches enacted in the two frameworks to organize a more rigorous and effective management of raw data by defining standard workflows. The scientific business processes for generation of the EVs and related indicators from raw data is increasingly formalized in the literature by specifying and explaining the necessary logical steps (Lehmann et al., 2020).

At present, the EBV-related literature provides examples of standard workflows; each of these is focusing on specific

\footnotetext{
${ }^{37} \mathrm{FOO}$ is the scientific and technological setting promoted after the OceanObs'09 Conference to establish a comprehensive global observing system, and to maximize integration of measurements from different domains.
}

biological processes and thus, ultimately, on individual variables. Kissling et al. (2018a,b), and Jetz et al. (2019) propose workflows for species abundance (SA) and distribution (SD), population abundance, and species traits. They aim at improving accessibility in all phases of the data life cycle by identifying a detailed and common processing procedure to openly integrate any record in global data products. The SA/SD workflow was recently tested with data supplied by two biodiversity IT facilities (i.e., GBIF, ALA) (Hardisty et al., 2019a). In 2021, the beta version for the EBVs portal ${ }^{38}$ was released: It demonstrates which metrics the EBVs will represent and which outputs will be achieved through common work streams.

Analogous workflow-derived products are outlined for oceanographic data in the work of Buck et al. (2019) and for the BioEco EOVs. Currently, the BioEco EOV workflows are organized mainly at the habitat and taxon levels. For example, due to the two decades of coordinated coral reef monitoring undertaken by the Global Coral Reef Monitoring Network (GCRMN), the BioEco EOV "Hard coral cover and composition" is one of the most globally coordinated and advanced workflow (GCRMN, 2019). The GCRMN adopted a model that maximizes submission of raw data meeting a minimum quality level (Obura et al., 2019) from all parts of the globe. It identifies three levels to describe quality of data and provides specific guidance to increase quality from level 1 to 3 , by including also preparation of appropriate metadata.

The Continuous Plankton Recorder (CPR) surveys represent an invaluable source of data for the "Phytoplankton Diversity" biological EOV and already inform indicators for the EU Marine Strategy Framework Directive (McQuatters-Gollop et al., 2015). This program provides highly resolved (i.e., species-level taxonomy) data together with abundances at large spatial and temporal scale by leveraging on methodological similarities of the surveys (Batten et al., 2019). This program also provides evidence of the limits of and the solutions needed for integrating data from the five regional $\mathrm{CPR}$ surveys. While not fully global (Bax et al., 2019), the CPR surveys will be expanded to other key areas and integrated with other observing systems (Batten et al., 2019).

A more high-level and cross-variable categorization of the BioEco EOV data and data products is illustrated in the work of Lear et al. (2020). It allows to better understand the different types of European biology data and their products provided by EMODnet ${ }^{39}$ with reference to the GOOS framework. The workflow facilitates assessment of the fitness-for-purpose of the accessed information by the community of data consumers. This is done through classification of datasets in distinct levels according to the amount of processing and/or analysis that has taken place to bring the primary measurements to a particular intermediate product.

The quality checks as well as the logical steps illustrated in these works, aimed at processing observations into more

\footnotetext{
${ }^{38}$ https://portal.geobon.org/index. Accessed April 29, 2021.

${ }^{39}$ https://www.emodnet-biology.eu/about-atlas. Accessed April 29, 2021.
} 
informative datasets or indicators (Kissling et al., 2018a), should be considered by local observing elements.

\section{Phase 2. Comparison of GOV Practices and Guidelines}

The second result of our approach consists of assessing compliance of the data collection and management practices adopted in the GOV with the guidelines derived, respectively, from the literature on the $\mathrm{EBV}$ s and the BioEco EOVs. Table 2 summarizes the result of this Phase, i.e., whether the guidelines are followed and to which extent the data management practices satisfy the Benson's tenets.

As regards the guidelines related to tenet 1 , analysis of the DEIMS-SDR metadata and of the 50-year dataset allows us to identify the primary in situ observations collected in the GOV that are useful for calculating the EVs. The observed and/or measured properties are reported in Table 3 (column 1) and are linked to EBVs (columns 10, 11) and BioEco EOVs, also by categorizing the observations according to the GOOS classification [i.e., sub-variables, supporting variables, complementary variables, and derived product (columns 1-9)].

Analysis of the DEIMS-SDR metadata allowed us to identify which EBVs the managers of the GOV declare to measure for the marine GEO BON biome. The GOV monitors 2 EBVs (i.e., species distribution and abundance) for 2 groups of organisms (phyto- and zoo-plankton). Data are obtained from campaignbased measures, with a sampling rate spanning from weekly to monthly frequencies. For abiotic measurements, the GOV also relies on the Acqua Alta Oceanographic tower (Ravaioli et al., 2016). Moreover, sub-, supporting, and complementary variables of phyto- and zoo-plankton biomass and diversity are collected; from these variables, the derived products obtained are illustrated in Table 3.

The taxonomic ranks detected through observation are heterogeneous and groupings are generally limited to class level (e.g., Diatoms, Dinoflagellates, Coccolithophores for phytoplankton). They are indicated as free text in field definitions.

For what concerns compliance with the guidelines identified in the BioEco EOV framework, the methodologies used for collecting and analyzing phyto- and zoo-plankton abundancies and biomass are detailed in the data paper describing the 50-year GOV dataset (Acri et al., 2020), which also takes into account the historical methodological changes occurred.

Phytoplankton abundance and total biomass are measured by using two different methods: Chlorophyll fluorescence (Lorenzen, 1966) and inverted microscopy (Lund et al., 1958). Both these methods are ranked as Best and Acceptable, respectively, in the related GOOS TSS and best practice (Lorenzoni and Benway, 2013).

Zooplankton is collected through plankton tows (Harris et al., 2000), ranked as Best method in Lorenzoni and Benway (2013); abundance is measured through visual counting (stereo microscopy) (Harris et al., 2000) which is not listed among the sampling and analytical specifications.
Methods used for analyzing phyto- and zoo-plankton abundancies and biomass are the most commonly used by marine ecologists, so their biases (Costello et al., 2017) are not expressively indicated neither in the metadata nor in the dataset. The taxonomic revision of the phytoplankton species has been made according to "Algaebase" of taxonomic, nomenclatural, and distributional information. For the zooplankton species, the Marine Planktonic Copepods catalogue $^{41}$ (Razouls et al., 2005-2021) has been used. In the past, for phytoplankton and zooplankton analyses, several texts and monographs were used (Peragallo, 1908; Pascher, 1913; Hustedt, 1962a,b; Hendey, 1964; Rampi and Bernhard, 1980; Heimdal, 1993; Throndsen, 1993; Tomas, 1997; Bérard-Therriault et al., 1999; Harris et al., 2000).

Information on instruments, sampling, and analytical methods for each parameter are recorded in specific fields in the dataset: They were compiled from both bibliographic references and interviews with active and retired researchers. When they are not available, this is clearly indicated in order to allow for appropriate assessment of fitness-for-use. Methods, including sensors, have been also described by separated metadata using the Open Geospatial Consortium (OGC) SensorML v2.0 standard (OGC, 2014) enriched with terms from the BODC NERC Vocabulary Server (NVS) ${ }^{42}$.

As regards the guidelines concerning tenet 2, neither the DEIMS-SDR metadata nor the six tasks of the EcoNAOS initiative and the description of the GOV dataset allow for relating local measurements to global and national policy reporting requirements. In fact, information on compliance with international conventions and country or community directives are not provided in metadata. EcoNAOS targeted dissemination of results to the scientific audience and it is accessible on the Web without restrictions, but the decision-makers in natural resource management are not directly involved as beneficiaries of the research and monitoring outputs.

With respect to the guidelines concerning tenet 3 , the dataset was not deposited in GBIF/OBIS and the standards for data and metadata were different from those suggested by the GOOS and GEO BON communities. The Bari Manifesto principles were not followed nor activities were planned to help conversion between data and metadata formats.

Nevertheless, the six tasks of EcoNAOS can be considered FAIR-oriented practices [for Findable, Accessible, Interoperable, and Reusable management of data (Wilkinson et al., 2016)]. In fact, tasks 2 (Rescue of available metadata), 3 (Integration of historical time series in an interoperable data infrastructure), and 5 (Dynamic citation for time series) contribute at making data findable; tasks 3, 4 (Publication of ideas and tools for processing time series), and 6 (Output guidelines) focus on data accessibility while task 1 (Harmonization of measurements of time series) and 3 address interoperability of data; reuse of the recovered data is addressed by task 2 .

\footnotetext{
${ }^{40}$ https://www.algaebase.org. Accessed April 30, 2021.

${ }^{41}$ https://copepodes.obs-banyuls.fr/en/links.php. Accessed April 30, 2021.

${ }^{42}$ https://vocab.nerc.ac.uk/. Accessed April 30, 2021.
} 
TABLE 2 | The compliance matrix.

\begin{tabular}{|c|c|c|}
\hline $\begin{array}{l}\text { Key-tenets (Benson et al., } \\
\text { 2018) }\end{array}$ & EBVs (Pereira et al., 2013) & BioEco EOVs (Miloslavich et al., 2018) \\
\hline 1. Standardized Data Collection & $\begin{array}{l}\text { Identification of the in situ observations can be desumed by site } \\
\text { metadata in the DEIMS-SDR; the spatial and temporal extents } \\
\text { of the observations specified in site metadata; adoption of } \\
\text { classification systems for taxonomic revision (i.e., Algaebase, } \\
\text { Marine Planktonic Copepods catalog); changes to the method } \\
\text { described in dataset metadata; methods (including sensors) } \\
\text { described using SensorML and NERC Vocabularies; biases on }\end{array}$ & $\begin{array}{l}\text { Phytoplankton abundance and total biomass measured by } \\
\text { using, respectively, microscopy (inversion chamber), taxonomy } \\
\text { and Chlorophyll fluorescence; zooplankton collected through } \\
\text { plankton tows; abundance measured through visual counting } \\
\text { (stereo microscopy); changes to the methods are described in } \\
\text { dataset metadata }\end{array}$ \\
\hline
\end{tabular}

2. Addressing Global Reporting Needs

3. Making Data FAIR

4. Analytical Algorithms, Tools, and Workflows Are Accessible and NERC Vocabularies; biases on the methods across time not recorded in metadata

Policy reporting requirements not provided in the DEIMS-SDR metadata; end-users involvement not planned in EcoNAOS approach

Adoption of delimited text files (CSV) as standard for data tables; the JSON format for metadata exchange; adoption of the DEIMS-SDR information system; collection/analytical methods and unit of measure described in the GOV dataset; compliance with OGC adoption of standards for sharing biotic and abiotic observations (SOS, SensorML, and O\&M); OBIS/GBIF not used to deposit data; DwC-A and related extensions not used to represent data

Open-source code for management, sharing, and visualization of data (GET-IT); open-source code for structural and syntactical harmonization of historical time series; lack of compliance with quality checks and steps described in the Species abundance/distribution workflow and EMODnet; global workflows to build EV data products not considered

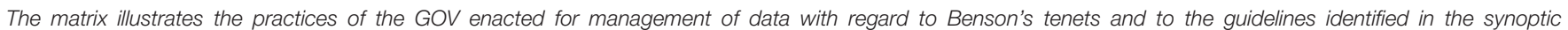
comparison matrix.

The dataset is accessible both as a tabular structure in the CSV format and via the OGC Sensor Observation Service $(\mathrm{SOS})^{43}$ (OGC, 2012). The coordinate format of the sampling points and the name of sampling stations were harmonized along the temporal axis; units of measure and metadata of instruments, sampling, and analytical methods are provided for each parameter. In the SOS version, the abiotic and biotic observations are encoded in the OGC Observation and Measurement (O\&M) ${ }^{44}$ schema (OGC, 2011); metadata of fixedpoint observing systems, laboratory instruments, and sensors are described by using the OGC SensorML v2.0 language by means of the open software GET-IT (Oggioni et al., 2017).

Also, the DEIMS-SDR is used by the GOV to make both the site information and the 50 -year datase $\mathrm{t}^{45}$ available. The DEIMSSDR metadata of the GOV dataset are serialized in JSON format. In previous versions of the DEIMS-SDR, exporting metadata in XML following EML 2.1 and ISO19139 schema was possible through a module (Wohner et al., 2019) that is currently disabled, but details on the transformation of metadata into EML is documented in Kliment and Oggioni (2011).

\footnotetext{
${ }^{43}$ For instance, the series of phytoplankton observations obtained by the use of the inverted microscope identified by the URL http://sp7.irea.cnr.it/sensors/ vesk.ve.ismar.cnr.it/procedure/noManufacturerDeclared/noModelDeclared/ noSerialNumberDeclared/20150903123743511_56166 is available, in Observation and Measurements format, at the url: http://vesk.ve.ismar.cnr.it/observations/ sos $/$ kvp? service $=S O S \&$ version $=2.0 .0 \&$ request $=$ GetObservation \&procedure $=h t t p$ : //sp7.irea.cnr.it/sensors/vesk.ve.ismar.cnr.it/procedure/noManufacturerDeclared/ noModelDeclared/noSerialNumberDeclared/20150903123743511_56166 (Accessed April 29, 2021).

${ }^{44}$ Observations and Measurement is one of the suggested standard for data exchange in INSPIRE (Temporary MIG subgroup for action MIWP-7a, 2016). It was also proposed in past discussions of TDWG (Cox and Lefort, 2008) and its exploitation was considered to foster interoperability of biological information (Watkins, 2012; Oggioni et al., 2016).

${ }^{45}$ https://deims.org/dataset/38d604ef-decb-4d67-8ac3-cc843d10d3ef. Accessed April 29, 2021.
}

As regards the guidelines associated with tenet 4, the workflows identified both in the GEO BON and GOOS frameworks are not specifically considered by the GOV. Nevertheless, the tenet 4 results satisfied by task 4 of EcoNAOS, which established releasing the code for cleaning-up, re-ordering and organizing the dataset, by offering an automatic and accessible procedure for the recovery of historical time series. The code is freely available under the GNU GPL v.3 License both on GitHub ${ }^{46}$ and in Zenodo (Minelli, 2020). Data visualization is ensured by the open software GET-IT, compliant with OGC specifications.

\section{DISCUSSION}

The main goal of this study is to foster reuse of the long-term biodiversity observations in the EV frameworks. We elaborated a synoptic, up-to-date overview of the guidelines for implementing Benson's tenets on the basis of analysis and elaboration of the literature related to Essential Biodiversity/Ocean Variables. Then we benchmarked the identified guidelines against the current practices of a specific case study, i.e., the GOV LTER-Italy site.

Particularly, our practical approach allows for mapping common or complementary guidelines in the two frameworks, which help make the tenets operative in daily planning of data maintenance activities. The tenets represent a sound, synthetic vision for coordinated and multi-dimensional management of measures. However, data providers have some freedom when translating them into actions to enable reuse of local data for EV estimation, thus ultimately producing heterogeneous contributions from observing systems. This issue is addressed and thoroughly analyzed in the case study we presented.

${ }^{46}$ https://github.com/CNR-ISMAR/econaos/tree/master. Accessed February 22, 2020. 
TABLE 3 | Contributions of the GOV to the GOOS and GEO BON frameworks

\begin{tabular}{|c|c|c|c|c|c|c|c|c|c|c|}
\hline \multirow{3}{*}{$\begin{array}{l}\text { GOV } \\
\text { observed/measured } \\
\text { property }\end{array}$} & \multicolumn{8}{|c|}{ BioEco EOV } & \multicolumn{2}{|c|}{ EBV } \\
\hline & \multicolumn{4}{|c|}{ Phytoplankton biomass and diversity } & \multicolumn{4}{|c|}{ Zooplankton biomass and diversity } & \multirow{2}{*}{$\begin{array}{l}\text { Species } \\
\text { abundance } \\
-\end{array}$} & \multirow{2}{*}{$\begin{array}{l}\begin{array}{l}\text { Species } \\
\text { distribution }\end{array} \\
-\end{array}$} \\
\hline & $\begin{array}{l}\text { Sub- } \\
\text { variables }\end{array}$ & $\begin{array}{l}\text { Supporting } \\
\text { variables }\end{array}$ & $\begin{array}{l}\text { Complementary } \\
\text { variables }\end{array}$ & $\begin{array}{l}\text { Derived } \\
\text { product }\end{array}$ & $\begin{array}{l}\text { Sub- } \\
\text { variables }\end{array}$ & $\begin{array}{l}\text { Supporting } \\
\text { variables }\end{array}$ & $\begin{array}{l}\text { Complementary } \\
\text { variables }\end{array}$ & $\begin{array}{l}\text { Derived } \\
\text { product }\end{array}$ & & \\
\hline Relative abundance & $x$ & & & & $x$ & & & & $x$ & \\
\hline Biomass & $x$ & & & & $x$ & & $x$ & & & \\
\hline $\begin{array}{l}\text { Pigment concentration } \\
\text { (Chlorophlyll a) }\end{array}$ & $x$ & & & & & & & & & \\
\hline Taxonomy/Diversity & $x$ & & & & $x$ & & $x$ & & & \\
\hline $\begin{array}{l}\text { Functional } \\
\text { types/groups }\end{array}$ & & & & $x$ & & & & $x$ & & \\
\hline Diversity indexes & & & & $x$ & & & & & & \\
\hline Spatial distribution & & & & $x$ & & & & $x$ & & $x$ \\
\hline Nutrients & & $x$ & & & & & & & & \\
\hline Temperature & & $x$ & & & & & $x$ & $x$ & & \\
\hline Salinity & & $x$ & & & & & & $x$ & & \\
\hline Oxygen & & $x$ & & & & & & & & \\
\hline $\mathrm{pH}$ & & $x$ & & & & & & & & \\
\hline $\mathrm{pCO}_{2}$ & & $x$ & & & & & & & & \\
\hline Currents & & & & & & & $x$ & & & \\
\hline
\end{tabular}


In fact, even if the data management practices of the GOV satisfy tenet 1 (Standardized data collection), 3 (Making data FAIR), and 4 (Analytical algorithms, tools, and workflow are accessible), comparison with the guidelines allows us to pinpoint the missing actions and the information needed to improve quality of the contribution to the EV frameworks.

For example, as regards tenet 1: (i) methodologies applied by the GOV are ranked high in the Ocean Best Practices (Lorenzoni and Benway, 2013), (ii) sensors and methods are described through specific metadata, and (iii) classification systems are used to review and harmonize the taxonomy of primary datasets. Nevertheless, methodologies and their biases (Costello et al., 2017) are not documented in the DEIMS-SDR metadata of the dataset. Also, thesauri are not used to describe the taxonomic and/or ecological communities neither in the metadata nor in the dataset. This information should be added, since only the properties observed by sensors are linked to terms in standard vocabularies. Also, the metadata of datasets should be completed with information on the method applied to correct the bias introduced by the investigator taxonomical experience, which is currently provided in the data paper (Utermöhl, 1958).

As regards tenet 3 , the GOV employs standards to format (i.e., CSV), structure (i.e., OGC O\&M), and publish (i.e., OGC SOS) the dataset in order to facilitate exchange of information among systems and effectively making the 50-years dataset accessible by global applications. However, its current structure doesn't fulfill the DwC-A requirements. The conversion of time series in this new schema is beneficial to publishing data in OBIS/GBIF and also in regional nodes (e.g., EurOBIS). Automatic mapping procedures/scripts to link the fields of the data table with the appropriate DwC terms are not available. Notably, in the analyzed case study, the use of OGC services ensures that data are already formatted in O\&M. This OGC schema natively supports the same semantic annotation strategy suggested by OBIS in DwC eMoF, that is, using URIs of semantic vocabulary terms (Rosati et al., 2017; Tagliolato et al., 2019). Moreover, the terms exploited for the use case are from NVS, one of the OBIS eMoF recommended sources. These commonalities should ease adaptation of the current O\&M format to the OBIS eMoF and constitute the starting point for the design of a community-adopted tool.

In Supplementary Tables 3-5 we propose a mapping ${ }^{47}$ of the O\&M profile in which the data of our case study are schematized, into one among the possible profiles of $\mathrm{DwC}$ eMoF (namely, the 6th option discussed in De Pooter et al., 2017).

Moreover, considering CSV serialization of the dataset, given that the SOS server provides very detailed descriptions of instruments, we think that an improvement could be providing, together with the sole name of methods/instruments, also the URIs of SensorML documents. This practice follows a metadata delegation strategy (Fugazza et al., 2021) similar to the practices fostered by the $\mathrm{DwC}$ eMoF.

Also, tenet 4 is complied with by the GOV since the scientific staff involved in management of time series share the code for

\footnotetext{
${ }^{47}$ In Supplementary Material we provide the complete mapping for the use case, and we formalize it by means of executable code excerpts, hence the proposal constitutes the basis for an actual software implementation.
}

organizing the database in an open repository and release open software for data visualization through OGC services (Minelli, 2020). By comparing the practices to the guidelines identified in Table 2, we also identify regional (e.g., EMODnet) and global workflows to which the GOV could refer to for executing aggregation and/or processing of Essential Ocean/Biodiversity Variable observations. Particularly, the SP/SD workflows should be considered for assuring standardized building of derived products. Also, the EMODnet Biology work stream (Lear et al., 2020) is a suitable reference to be applied in this case study, since the former is designed for development of stakeholder-driven data products to support conservation and advisory decisions, which is a dimension of data management not already addressed by the GOV site.

Comparison of the GOV practices with the guidelines related to tenet 2 highlights that global and European policy relevance of the collected data is not considered when modeling data products. We suggest that these details, if present in informative sources not consulted in this study, need to be easily discoverable though public and digital access to the data (Lehmann et al., 2020). Conversely, if policy application is not taken into account in the monitoring activities, targeted actions linking science to policy should be considered (e.g., dissemination of results to national environmental agencies, involvement of stakeholders to derive data products, evaluation of fulfillment of national monitoring/informative gaps). Long-term time series, especially those of phytoplankton, are very important to stakeholders for evaluating policies aimed at addressing eutrophication and pollution (Lear et al., 2020). Agreements and international conventions which could benefit from data can be specified together with the level of contribution (i.e., potential, operative) in the appropriate element provided in the site metadata model of the DEIMS-SDR (i.e., Reporting, Legal act).

Moreover, through analysis of the literature, we highlighted that an extensive work to link the EOV framework to the European regulations is needed in order to support harmonized data management practices.

At present, the informative sources considered for analyzing data management practices of the GOV site are scattered through different web services and online resources. This suggests that it is not currently possible to perform assessment through a unique point of access to information. Nevertheless, a comprehensive evaluation along the dimensions entailed by the Benson's tenets is largely based on metadata, and particularly on the information published by the DEIMS-SDR, which already host multiple entry types from 700 long-term sites of ILTER (Mirtl et al., 2018). With appropriate metadata, extensive analysis on the data capacity of sites or regional networks could be performed. An online survey, launched by the GOOS BioEco Panel in November 2019, reached the ILTER national networks and sites, among other initiatives, to map and highlight observing systems that are taking part, or aspire to join, the global ocean observing network for biology to support the science and management of marine biodiversity and its societal benefits. Representing in an unbiased manner the contributions to the $\mathrm{EV}$ frameworks of local and/or regional networks could be facilitated by exploiting already implemented IT tools. 
The informative sources we consulted were quite complete and already inclusive of the researchers' experiences, thus allowing us to describe the aptitude and experience of the scientific staff, without consulting the members through questionnaire and by saving survey time. Especially, mature capacity to recover the historical series is present but would benefit of IT tools bridging the (meta)data standards across science disciplines. In fact, as will be stressed in the recommendations reported below, further data wrangling activities (Parsons et al., 2004) will be required to transform the GOV historical data from one format into another with the intent of making it more appropriate and valuable for a different downstream purpose.

Our approach allows for listing specific recommendations to help the GOV scientific staff design technological tools and curation interventions.

The recommendations are:

- As regards tenet 1 , methodologies should be described directly within the metadata of the dataset in the DEIMS-SDR, by providing information on the bias (Costello et al., 2017). Information on the methodologies should be introduced in metadata; vocabularies and thesauri should be adopted to represent taxonomic and/or ecological communities.

- As regards tenet 2, policy reporting requirements need to be considered when disseminating data to end-users and when modeling data products from historical time series. The policy relevance of the observations must be made discoverable by improving the metadata. We consider this recommendation useful also for tenet 5 , which is not specifically examined in this work.

- As regards tenet 3, the GBIF/OBIS requirements should be checked to deposit measurements in these data repositories or obtain interoperability with standards adopted by OBIS so that contribute to foster the automatically harvesting of the data. The mapping we provide in Supplementary Tables 3-5, could constitute the basis for a software implementation in this sense.

- As regards tenet 4 , the workflows for processing data: (i) around specific EVs, (ii) in regional communities (e.g., EMODnet) and by aligning to an observing element of GOOS (e.g., CPR) need to be considered in deriving data products.

Also, implementation of these recommendations could be useful to test effectiveness of the guidelines for making management of the 50-year dataset more reusable at global scale and to improve the current collection of in situ observations.

These recommendations are specific for the selected case study. Nevertheless, they emphasize some common issues present in the scientific community working on biodiversity. For example, recommendations for tenets 1 and 3 highlight that metadata are increasingly adopted by researchers but they are not always exhaustively compiled. Metadata incompleteness has already been stressed as a common issue in ecological data sharing (Kervin et al., 2013; Lear et al., 2020) and specifically in the LTER-Italy community (Zilioli et al., 2019), preventing the data consumer from interpreting and re-using the data for new purposes. The recommendation for tenet 3 confirms interoperability as a critical issue, crucial to increasing openness and integration of biodiversity measurements, as already evidenced in Klein et al. (2019) and Snowden et al. (2019). This is confirmed by the fact that, currently, OBIS only hosts a few LTER datasets ${ }^{48}$ : A number not representative of the estimated LTER data resources for marine biodiversity made available by the DEIMS-SDR and DataONE (Mollenhauer et al., 2018; Muelbert et al., 2019).

These recommendations can be applied to other LTER sites and for other EVs after appropriate analysis, according to Phase 2. However, the results of this study and the adopted approach can be beneficial to other LTER marine sites in different countries within ILTER. The eLTER-RI could also rely on our analysis and recommendations. In fact, the recent data calls ${ }^{49}$ launched in the eLTER-RI context demonstrate the fragmented scenario of data management practices across different networks wherever handling decisions are up to the single provider. The presented approach can be used by site managers and scientific staff to organize sites and/or networks resources so as to identify common needs in preserving time series. Focusing support in data management around reuse of time-series for EVs can strengthen coordination of sites within these global frameworks.

\section{CONCLUSION}

In the last decade, the EV frameworks developed pathways to deliver science-based information to decision makers and to review robustness of policy reporting requirements (Vihervaara et al., 2017; Muller-Karger et al., 2018; Guerra et al., 2019). The EV frameworks represent key initiatives for achieving global assessment of the status of biodiversity by federating data contributors worldwide. Nevertheless, without engagement of local, long-term research and monitoring programs in these frameworks, volumes of multi-decadal time series suitable for detecting changes and effects of management policies remain underutilized.

We identified in the literature a set of common and coordinated guidelines promoted by different groups working on Essential Biodiversity/Ocean Variables, so as to enable reuse of marine biodiversity observations in both these partly overlapping and still complementary frameworks. The guidelines were arranged in a synoptic comparison matrix. The existing observing systems can benefit from this matrix, which can be used to improve management procedures for the marine biodiversity measurements that are required for global studies and observing programs. Also, the guidelines can be updated according to the progresses achieved by the GOOS and GEO BON communities as well as through dialog among decision makers and scientists (Bax et al., 2019).

\footnotetext{
${ }^{48}$ The dataset is published under the EMODnet Biology agreement with a specific project commit which doesn't involve the whole European LTER networks.

${ }^{49} \mathrm{https} / / /$ www.lter-europe.net/projects/PLUS/call-for-ecosystem-andbiodiversity-data. Accessed April 26, 2021.
} 
Then, as suggested in Benedetti-Cecchi et al. (2018), we proposed concrete connections between the frameworks and a local initiative through data management harmonization. By means of the compliance matrix, we compared the data handling practices of the LTER-Italy GOV site with the guidelines set by the EV frameworks. We do so by highlighting a case-specific exemplification of the key-tenets envisioned by Benson. Finally, we identified the recommendations for improving data curation of the GOV historical time series (Benson et al., 2018).

The recommendations set out the path to fostering inclusion of the marine component of ILTER in the network supporting the GOOS (Muelbert et al., 2019), as a practical example of how the LTER in situ parameters, with appropriate data curation, may fit into global frameworks for biodiversity assessment.

Extension of the approach to other case studies is not limited to the LTER networks and depends on the information provided by in situ observing system for the analysis. The approach can help provide a more accurate and realistic representation of the difficulties hampering standard adoption by the scientific community working on biodiversity (Snowden et al., 2019); it also eases contributing data to the policy-science community through the EVs.

The ILTER marine component and GOOS/MBON can mutually benefit from setting similar requirements and deciding what to measure and how to preserve records; sharing deployment and maintenance of instrumentation can be also beneficial (Haase et al., 2018). Moreover, identification of common paths to reusability of data, as well as assessment of policy and/or legal bottlenecks, could foster broader data sharing. Efforts in this direction are just at an early stage but they are considered crucial to overcoming fragmentation among sites, improving interfaces among networks, and promoting cooperation on shared environmental issues and targets (Haase et al., 2018; Muelbert et al., 2019).

\section{DATA AVAILABILITY STATEMENT}

The original contributions presented in the study are included in the article/Supplementary Material, further inquiries can be directed to the corresponding author/s.

\section{AUTHOR CONTRIBUTIONS}

$\mathrm{CB}$ performed the case study analysis as regards the methodological comparison, wrote and reviewed the manuscript,

\section{REFERENCES}

Acri, F., Bastianini, M., Bernardi Aubry, F., Boldrin, A., Camatti, E., Bergami, C., et al. (2019). LTER Northern Adriatic Sea (Italy) Marine Data From 1965 to 2015 (Version 3) [Data set]. Geneva: Zenodo. doi: 10.5281/zenodo.351 6717

Acri, F., Bastianini, M., Aubry, F. B., Camatti, E., Boldrin, A., Bergami, C., et al. (2020). A long-term (1965-2015) ecological marine database from the LTERItaly Northern Adriatic Sea site: plankton and oceanographic observations. Earth System Sci. Data 12, 215-230. doi: 10.5194/essd-12-215-2020 and compiled Tables 2, 3. PC collaborated to conceptualize, design, and reorganize the manuscript and contributed to significant reviews of the versions of the manuscript. CF reorganized the structure of the manuscript and provided detailed reviews of the versions of the manuscript. AO performed the analysis of the case study as regards both the methodological and the technological comparison, reviewed the manuscript, compiled Tables 2, 3, and also assigned funds for the submission of the study. AP wrote the manuscript, provided suggestions to integrate and join up the manuscript with further contents, and reorganized the manuscript with significant reviews of its versions. PT performed the analysis and discussion as regards the technological issues, wrote, reorganized, and significantly reviewed the manuscript and bibliography, and carried out the SOS/O\&M mapping into DwC-A eMoF presented in the Supplementary Material. MZ conceived and wrote the manuscript, designed the research, carried out the literature, policy, and technological analysis and case study comparison, and produced tables and Figure 1. All authors contributed to the article and approved the submitted version.

\section{FUNDING}

The activities described in this manuscript have been partially funded by eLTER PLUS H2020 (Grant agreement No. 871128) and by the Italian National Program (2017-2019) for the Implementation of the Union Framework for the collection, management and use of data in the fisheries sector [Regulation (EU) 2017/1004].

\section{ACKNOWLEDGMENTS}

The authors are grateful to the reviewers for their careful reading of this manuscript and their useful comments and suggestions.

\section{SUPPLEMENTARY MATERIAL}

The Supplementary Material for this article can be found online at: https://www.frontiersin.org/articles/10.3389/fmars. 2021.645997/full\#supplementary-material

Anonymous (2019). Essential biodiversity. Nat. Ecol. Evol. 3:503. doi: 10.1038/ s41559-019-0870-x

Batten, S. D., Abu-Alhaija, R., Chiba, S., Edwards, M., Graham, G., Jyothibabu, R., et al. (2019). A global plankton diversity monitoring program. Front. Mar. Sci. 6:321. doi: 10.3389/fmars.2019.00321

Bax, N. J., Miloslavich, P., Muller-Karger, F. E., Allain, V., Appeltans, W., Batten, S. D., et al. (2019). A response to scientific and societal needs for marine biological observations. Front. Mar. Sci. 6:395. doi: 10.3389/fmars.2019.00395

Benedetti-Cecchi, L., Crowe, T., Boehme, L., Boero, F., Christensen, A., Gre ìmare, A., et al. (2018). "Strengthening Europe's capability in biological ocean 
observations," in Future Science Brief 3 of the European Marine Board, eds A. M. Piniella, P. Kellett, K. Larkin, and S. Heymans (Ostend: European Marine Board), 3 .

Benson, A., Brooks, C. M., Canonico, G., Duffy, E., Muller-Karger, F., Sosik, H. M., et al. (2018). Integrated observations and informatics improve understanding of changing marine ecosystems. Front. Mar. Sci. 5:428. doi: 10.3389/fmars.2018. 00428

Bérard-Therriault, L., Poulin, M., and Bosse, L. (1999). Guide D'identification $d u$ Phytoplancton Marin de L'estuaire et du Golfe du Saint-Laurent: Incluant e iGalement Certains Protozoaires. Ottawa, ON: NRC Research Press, 128.

Biermann, F., Kanie, N., and Kim, R. E. (2017). Global governance by goal-setting: the novel approach of the UN sustainable development goals. Curr. Opin. Environ. Sustain. 26-27, 26-31. doi: 10.1016/j.cosust.2017.01.010

Bojinski, S., Verstraete, M., Peterson, T. C., Richter, C., Simmons, A., and Zemp, M. (2014). The concept of essential climate variables in support of climate research, applications, and policy. Bull. Am. Meteorol. Soc. 95, 1431-1443. doi: 10.1175/BAMS-D-13-00047.1

Bordogna, G., Fugazza, C., Tagliolato Acquaviva d'Aragona, P., and Carrara, P. (2021). Implicit, formal, and powerful semantics in geoinformation. ISPRS Int. J. Geo Inf. 10:330. doi: 10.3390/ijgi10050330

Buck, J. J. H., Bainbridge, S. J., Burger, E. F., Kraberg, A. C., Casari, M., Casey, K. S., et al. (2019). Ocean data product integration through innovation-the next level of data interoperability. Front. Mar. Sci. 6:32. doi: 10.3389/fmars.2019.00032

Canonico, G., Buttigieg, P. L., Montes, E., Muller-Karger, F. E., Stepien, C., Wright, D., et al. (2019). Global observational needs and resources for marine biodiversity. Front. Mar. Sci. 6:367. doi: 10.3389/fmars.2019.00367

Costello, M. J., Basher, Z., McLeod, L., Asaad, I., Claus, S., Vandepitte, L., et al. (2017). "Methods for the study of marine biodiversity," in The GEO Handbook on Biodiversity Observation Networks, eds M. Walters and R. J. Scholes (Cham: Springer), 129-163. doi: 10.1007/978-3-319-27288-7 6

Cox, S., and Lefort, L. (2008). "A standard information transfer model scopes the ontologies required for observations," in Proceedings of the TDWG 2008, 1924 October 2008, Maritime Museum of Western Australia (Geneva: Biodiversity Information Standards (TDWG)).

De Pooter, D., Appeltans, W., Bailly, N., Bristol, S., Deneudt, K., Eliezer, M., et al. (2017). Toward a new data standard for combined marine biological and environmental datasets - expanding obis beyond species occurrences. Biodivers. Data J. 5:e10989. doi: 10.3897/BDJ.5.e10989

Fugazza, C., Tagliolato Acquaviva d'Aragona, P., Oggioni, A., and Carrara, P. (2021). Decentralized geospatial metadata management delegating properties in the web of data. Earth Sci. Inform. 14, 1579-1596. doi: 10.1007/s12145-02000559- 1

GCRMN (2019). GCRMN Implementation and Governance Plan. Nairobi: United Nations Environment Programme.

Geijzendorffer, I. R., Regan, E. C., Pereira, H. M., Brotons, L., Brummitt, N., Gavish, Y., et al. (2016). Bridging the gap between biodiversity data and policy reporting needs: an essential biodiversity variables perspective. J. Appl. Ecol. 53, 1341-1350. doi: 10.1111/1365-2664.12417

Geldmann, J., Deguignet, M., Balmford, A., Burgess, N. D., Dudley, N., Hockings, M., et al. (2021). Essential indicators for measuring site-based conservation effectiveness in the post-2020 global bio-diversity framework. Conserv. Lett. e12792. doi: $10.1111 /$ conl.12792

Guerra, C., Pendleton, L., Drakou, E., Proenc, A. V., Appeltans, W., Domingos, T., et al. (2019). Finding the essential: improving conservation monitoring across scales. Glob. Ecol. Conserv. 18:e00601. doi: 10.1016/j.gecco.2019.e0 0601

Haase, P., Tonkin, J. D., Stoll, S., Burkharde, B., Frenzel, M., Geijzendorffer, I. R., et al. (2018). The next generation of site-based long-term ecological monitoring: linking essential biodiversity variables and ecosystem integrity. Sci. Total Environ. 613, 1376-1384. doi: 10.1016/j.scitotenv.2017.08.111

Hardisty, A. R., Belbin, L., Hobern, D., McGeoch, M. A., Pirzl, R., Williams, K. J., et al. (2019a). Research infrastructure challenges in preparing essential biodiversity variables data products for alien invasive species. Environ. Res. Lett. 14:025005. doi: 10.1088/1748-9326/aaf5db

Hardisty, A. R., Michener, W. K., Agosti, D., Alonso Garcia, E., Bastin, L., Belbin, L., et al. (2019b). The Bari Manifesto: an interoperability framework for essential biodiversity variables. Ecol. Inform. 49, 22-31. doi: 10.1016/j.ecoinf.2018.11.003

Harris, R., Wiebe, P., Lenz, J., Skjoldal, H.-R., and Huntley, M. (2000). ICES Zooplankton Methodology Manual. Amsterdam: Elsevier.
Hagerman, S. M., Campbell, L. M., Gray, N. J., and Pelai, R. (2021). Knowledge production for target-based biodiversity governance. Biol. Conser. 255, 2021:108980. doi: 10.1016/j.biocon.2021.108980

Heimdal, B. R. (1993). "Modern coccolithophorids," in Marine Phytoplankton A Guide to Naked Flagellates and Coccolithophorids, ed. C. Tomas (San Diego, CA: Academic Press), 147-248. doi: 10.1016/b978-0-12-693010-8.50009-8

Hendey, N. I. (1964). An Introductory Account of the Smaller Algae of British Coastal Waters. Fishery Investigation Series. Pt. 5: Bacillariophyceae (Diatoms). London: Her Majesty's Stationery Office. 317.

Hoban, S., Bruford, M., D’Urban Jackson, J., Lopes-Fernandes, M., Heuertz, M., Hohenlohe, P. A., et al. (2020). Genetic diversity targets and indicators in the CBD post-2020 global biodiversity framework must be improved. Biol. Conserv. 248:108654. doi: 10.1016/j.biocon.2020.108654

Hustedt, F. (1962a). "DieKiesealgenvonDeutschland,O s̈terreichsundderSchwei zmit Berusichtigung der u b́rigen La n̈der Europas sowie der angrenzender Mehresgebiet," Rabenhorst's Kryptogamen-Flora von Deutschland, Oesterreich und der Schweiz, eds L. Rabenhorst and A. Grunow (Leipzig: E. Kummer), 161-348.

Hustedt, F. (1962b). "Dinoflagellatae (Peridineae) monografischer behandlung," Rabenhorst's Kryptogamen-Flora von Deutschland, Oesterreich und der Schweiz, (Leipzig: E. Kummer).

Inspire Thematic Working Group on Environmental Monitoring (2011). D2.8.III.7 INSPIRE Data Specification on Environmental Monitoring Facilities - Draft Guidelines. Ispra: European Commission Joint Research Centre.

ISO TC 211 (2013). ISO 19157:2013 Geographic Information - Data Quality. Geneva: Standard, International Organization for Standardization.

ISO TC 211 (2014). ISO 19115:2014 Geographic information - Metadata. Geneva: Standard, International Organization for Standardization.

Jetz, W., McGeoch, M. A., Guralnick, R., Ferrier, S., Beck, J., Costello, M., et al. (2019). Essential biodiversity variables for mapping and monitoring species populations. Nat. Ecol. Evol. 3, 539-551. doi: 10.1038/s41559-019-0826- 1

Jones, M., O’Brien, M., Mecum, B., Boettiger, C., Schildhauer, M., Maier, M., et al. (2019). Ecological Metadata Language Version 2.2.0. KNB Data Repository. doi: $10.5063 / \mathrm{f} 11834 \mathrm{t} 2$

Kervin, K. E., Michener, W. K., and Cook, R. B. (2013). Common errors in ecological data sharing. J. ESci. Librariansh. 2, $3-16$.

Kissling, W. D., Ahumada, J. A., Bowser, A., Fernandez, M., Fernandez, N., Alonso Garcia, E., et al. (2018a). Building essential biodiversity variables (EBVs) of species distribution and abundance at a global scale. Biol. Rev. 93, 600-625. doi: 10.1111/brv.12359

Kissling, W. D., Walls, R., Bowser, A., Jones, M. O., Kattge, J., Agosti, D., et al. (2018b). Towards global data products of essential biodiversity variables on species traits. Nat. Ecol. Evol. 2, 1531-1540. doi: 10.1038/s41559-018-0667-3

Klein, E., Appeltans, W., Provoost, P., Saeedi, H., Benson, A., Bajona, L., et al. (2019). Obis infrastructure, lessons learned, and vision for the future. Front. Mar. Sci. 6:588. doi: 10.3389/fmars.2019.00588

Kliment, T., and Oggioni, A. (2011). Metadatabase: EnvEurope Metadata Specification for Dataset Level. EnvEurope Project Report pd.a1.1.4, EnvEurope Project (LIFE08 ENV/IT/000339). Available online at: http://www.enveurope. eu/misc/PD_1_1_4_Kliment_Metadatabase_201112_final_v1.0.pdf (accessed August 2, 2021).

Lear, D., Herman, P., Van Hoey, G., Schepers, L., Tonne ì, N., Lipizer, M., et al. (2020). Supporting the essential - recommendations for the development of accessible and interoperable marine biological data products. Mar. Policy 117:103958. doi: 10.1016/j.marpol.2020.103958

Lehmann, A., Nativi, S., Mazzetti, P., Maso, J., Serral, I., Spengler, D., et al. (2020). Geoessential - mainstreaming workflows from data sources to environment policy indicators with essential variables. Int. J. Digital Earth 13, 322-338. doi: 10.1080/17538947.2019.1585977

Lindstrom, E., Gunn, J., Fischer, A., McCurdy, A., and Glover, L. (2012). A Framework for Ocean Observing. By The Task Team for An Integrated Framework for Sustained Ocean Observing. Paris: UNESCO.

Lorenzen, C. J. (1966). A method for the continuous measurement of in vivo chlorophyll concentration. Deep Sea Res. Oceanogr. Abstr. 13, 223-227. doi: 10.1016/0011-7471(66)91102-8

Lorenzoni, L., and Benway, H. (2013). Global Intercomparability in a Changing Ocean: An International Time-Series Methods Workshop, November 28-30, 2012. St. Georges: Bermuda Institute of Ocean Sciences. doi: 10.25607/OBP-12 
Lund, J. W. G., Kipling, C., and Le Cren, E. D. (1958). The inverted microscope method of estimating algal numbers and the statistical basis of estimations by counting. Hydrobiologia 11, 143-170. doi: 10.1007/bf0000 7865

Mace, G. M., Barrett, M., Burgess, N. D., Cornell, S. E., Freeman, R., Grooten, M., et al. (2018). Aiming higher to bend the curve of biodiversity loss. Nat. Sustain. 1, 448-451. doi: 10.1038/s41893-018-0130-0

Manea, E., Bongiorni, L., Bergami, C., and Pugnetti, A. (2020). "Challenges for marine ecological observatories to promote effective gms of natura 2000 network - the case study of ecoads in the Adriatic sea," in Governing Future Challenges in Mediterranean Protected Areas, eds L. Alfare and E. Ruoss (Roma: CNR).

McQuatters-Gollop, A., Edwards, M., Helaoue ẗ, P., Johns, D. G., Owens, N. J., Raitsos, D. E., et al. (2015). The continuous plankton recorder survey: how can long-term phytoplankton datasets con-tribute to the assessment of good environmental status? Estuarine Coast. Shelf Sci. 162, 88-97. doi: 10.1016/j.ecss. 2015.05.010

MEDITS Working Group (2017). MEDITS Survey. Instruction Manual 9, International Bottom Trawl Survey in the Mediterranean. Available online at: https://www.sibm.it/MEDITS\%202011/docs/Medits_Handbook_2017_ version_9_5-60417r.pdf (accessed August 2, 2021).

Miloslavich, P., Bax, N. J., Simmons, S. E., Klein, E., Appeltans, W., AburtoOropeza, O., et al. (2018). Essential ocean variables for global sustained observations of biodiversity and ecosystem changes. Glob. Change Biol. 24, 2416-2433. doi: $10.1111 / \mathrm{gcb} .14108$

Miloslavich, P., Seeyave, S., Muller-Karger, F., Bax, N., Ali, E., Delgado, C., et al. (2019). Challenges for global ocean observation: the need for increased human capacity. J. Oper. Oceanogr. 12, S137-S156. doi: 10.1080/1755876X. 2018.1526463

Minelli, A. (2020). Econaos Project Code. Geneva: Zenodo. doi: 10.5281/zenodo. 3600991

Minelli, A., Oggioni, A., Pugnetti, A., Sarretta, A., Bastianini, M., Bergami, C., et al. (2018). The project EcoNAOS: vision and practice towards an open approach in the northern Adriatic sea ecologicalobservatory. Res. Ideas Outcomes 4:e24224. doi: 10.3897/rio.4.e24224

Minelli, A., Sarretta, A., Oggioni, A., Bergami, B., Bastianini, M., Bernardi Aubry, F., et al. (2021). Opening marine long-term ecological science: lesson learned from the LTER-Italy site Northern Adriatic Sea. Front. Mar. Sci. 8:659522. doi: $10.3389 /$ fmars.2021.659522

Mirtl, M., Borer, E. T., Djukic, I., Forsius, M., Haubold, H., Hugo, W., et al. (2018). Genesis, goals and achievements of long-term ecological research at the global scale: a critical review of ILTER and future directions. Sci. Total Environ. 626, 1439-1462. doi: 10.1016/j.scitotenv.2017.12.001

Mollenhauer, H., Kasner, M., Haase, P., Peterseil, J., Wohner, C., Frenzel, M., et al. (2018). Longterm environmental monitoring infrastructures in Europe: observations, measurements, scales, and socio-ecological representativeness. Sci. Total Environ. 624, 968-978. doi: 10.1016/j.scitotenv.2017. 12.095

Muelbert, J. H., Nidzieko, N. J., Acosta, A. T. R., Beaulieu, S. E., Bernardino, A. F., Boikova, E., et al. (2019). ILTER - the international long-term ecological research network as a platform for global coastal and ocean observation. Front. Mar. Sci. 6:527. doi: 10.3389/fmars.2019.00527

Muller-Karger, F. E., Miloslavich, P., Bax, N. J., Simmons, S., Costello, M. J., Pinto, I. S., et al. (2018). Advancing marine biological observations and data requirements of the complementary essential ocean variables (EOVs) and essential biodiversity variables (EBVs) frameworks. Front. Mar. Sci. 5:211. doi: 10.3389/fmars.2018.00211

OBIS (2021). Darwin Core Archive and Dataset Structure. Obis manual, OBIS. Available online at: https://obis.org/manual/dataformat (accessed on August 2, 2021).

Obura, D. O., Aeby, G., Amornthammarong, N., Appeltans, W., Bax, N., Bishop, J., et al. (2019). Coral reef monitoring, reef assessment technologies, and ecosystem-based management. Front. Mar. Sci. 6:580. doi: 10.3389/fmars.2019. 00580

OGC (2011). Observations and Measurements - XML Implementation. OGC Implementation OGC10-025r1. Wayland, MA: Open Geospatial Consortium.

OGC (2012). OGC Sensor Observation Service Interface Standard, Version2.0. StandardOGC12-006. Wayland, MA: Open Geospatial Consortium.

OGC (2014). OGC SensorML: Model and XML Encoding Standard. Encoding Standard OGC-12-000. Wayland, MA: Open Geospatial Consortium.
Oggioni, A., Tagliolato, P., Fugazza, C., Pepe, M., Menegon, S., Pavesi, F., et al. (2017). "Interoperability in marine sensor networks through SWE services: the RITMARE experience," in Oceanographic and Marine Cross-Domain Data Management for Sustainable Development, Advances in Environmental Engineering and Green Technologies (Hersey, PA: IGI GLOBAL), 200-223. doi: 10.4018/978-1-5225-0700-0.ch009

Oggioni, A., Tagliolato, P., Schleidt, K., Carrara, P., Grellet, S., and Sarretta, A. (2016). "Biodiversity data interoperability issues: on the opportunity of exploiting O\&M for biotic data management," in American Geophysical Union, Ocean Sciences Meeting 2016. OD34A-2487.

Parsons, M. A., Brodzik, M. J., and Rutter, N. J. (2004). Data management for the cold land processes experiment: improving hydrological science. Hydrol. Process. 18, 3637-3653. doi: 10.1002/hyp.5801

Pascher, A. (1913). DieSu s̈swasser-floraDeutschlands:O S̈terreichsundderschweiz. Schaffhausen: G. Fischer, 3-4.

Pearlman, J., Bushnell, M., Coppola, L., Karstensen, J., Buttigieg, P. L., Pearlman, F., et al. (2019). Evolving and sustaining ocean best practices and standards for the next decade. Front. Mar. Sci. 6:277. doi: 10.3389/fmars.2019.00277

Peragallo, H. (1908). Diatomées Marines de France et des Districts Maritimes Voisins. J. Tempe're.

Pereira, H. M., Ferrier, S., Walters, M., Geller, G. N., Jongman, R. H. G., Scholes, R. J., et al. (2013). Essential biodiversity variables. Science 339, 277-278. doi: $10.1126 /$ science. 1229931

Peterseil, J., Parland-von Essen, J., Lukkarinen, A., Pursula, A., Oggioni, A., Zilioli, et al. (2020). Report on Data and ICT Needs From Research Challenges (RCs) to be Used in Virtual Access (VA). Deliverable D10.2, EU Horizon 2020 eLTER PLUS Project, Grant agreement No. 871128. Available online at: https://elter.atlassian.net/wiki/download/attachments/19792644/eLTER\% 20PLUS_Deliverable\%2010.2_Data_and_ICT_Requirements.pdf?api=v2 (accessed May 18, 2021)

Phang, S. C., Failler, P., and Bridgewater, P. (2020). Addressing the implementation challenge of the global biodiversity framework. Biodivers Conserv. 29, 30613066. doi: 10.1007/s10531-020-02009-2

Rampi, L., and Bernhard, M. (1980). Chiave per la Determinazione Delle Peridinee Pelagiche Mediteranee. Rio de Janeiro: Comitato Nazionale Energia Nucleare.

Ravaioli, M., Bergami, C., Riminucci, F., Langone, L., Cardin, V., Di Sarra, A., et al. (2016). The RITMARE Italian fixed-point observatory network (IFON) for marine environmental monitoring: a case study. J. Oper. Oceanogr. 9, S202-S214. doi: 10.1080/1755876X.2015.1114806

Razouls, C., Desreumaux, N., Kouwenberg, J., and de Bove'e, F. (20052021). Biodiversity of Marine Planktonic Copepods (Morphology, Geographical Distribution and Biological Data). Paris: Sorbonne University.

Rogers, A. D., Aburto-Oropeza, O., Appeltans, W., Assis, J., Ballance, L., Cury, P., et al. (2020). Critical Habitats and Biodiversity: Inventory, Thresholds and Governance. Washington, DC: World Resources Institute.

Rosati, I., Bergami, C., Stanca, E., Roselli, L., Tagliolato, P., Oggioni, A., et al. (2017). A thesaurus for phytoplankton trait-based approaches: development and applicability. Ecol. Inform. 42, 129-138. doi: 10.1016/j.ecoinf.2017.10.014

Snowden, D., Tsontos, V. M., Handegard, N. O., Zarate, M., O’ Brien, K., Casey, K. S., et al. (2019). Data interoperability between elements of the global ocean observing system. Front. Mar. Sci. 6:442. doi: 10.3389/fmars.2019.00442

Tagliolato, P., Fugazza, C., Oggioni, A., and Carrara, P. (2019). Semantic profiles for easing SensorML description: review and proposal. ISPRS Int. J. Geo Inf. 8:340. doi: $10.3390 /$ ijgi 8080340

Temporary MIG subgroup for action MIWP-7a (2016). D2.9 Guidelines for the Use of Observations Measurements and Sensor Web Enablement-Related Standards. European Commission INSPIRE Directive - Technical Guidance D2.9, INSPIRE Maintenance and Implementation Group (MIG). Brussels: EU Commission.

Throndsen, J. (1993). “The planktonic marine flagellates," in Marine Phytoplankton A Guide to Naked Flagellates and Coccolithophorids, ed. C. R. Tomas (Cambridge, MA: Academic Press), 7-131. doi: 10.1016/b978-0-12-693010-8. 50008-6

Tomas, C. R. (1997). Identifying Marine Phytoplankton. Amsterdam: Elsevier. UNEP CBD, COP (2010). UNEP/CBD/COP/DEC/X/2 Decision Adopted by the Conference of the Parties to the Convention on Biological Diversity at its Tenth Meeting. UNEP Decision UNEP/CBD/COP/DEC/X/2, United Nations Environment Program (UNEP). Available online at: https://www.cbd.int/doc/ decisions/cop-10/cop-10-dec-02-en.pdf (accessed May 20, 2021).

UNEP CBD, COP (2012). UNEP/CBD/COP/DEC/X/2 Decision Adopted by the Conference of the Parties to the Convention on Biological Diversity at its 
Tenth Meeting. UNEP Decision UNEP/CBD/COP/DEC/XI/3, United Nations Environment Program (UNEP). Available online at: https://www.cbd.int/doc/ decisions/COP-11/cop-11-dec-03-en.pdf (accessed May 20, 2021).

UNEP CBD, SBI (2016). Remote Sensing of Essential Biodiversity Variables. UNEP Information UNEP/CBD/SBI/1/INF/49, United Nations Environment Program (UNEP). Available online at: https://www.cbd.int/doc/meetings/sbi/ sbi-01/information/sbi-01-inf-49-en.pdf (accessed May 20, 2021).

UNEP CBD, SBSTTA (2011). XV/1 Indicator Framework for the Strategic Plan for Biodiversity 2011-2020 and the Aichi Biodiversity Targets. SBSTTA Recommendation XV/1, United Nations Environment Program (UNEP). Available online at: https:/www.cbd.int/kb/record/recommendation/12968 (accessed May 20, 2021).

UNEP CBD, SBSTTA (2020). Post-2020 Global Biodiversity Framework: Scientific and Technical Information to Support the Review of the Updated Goals and Targets, and Related Indicators and Baselines. Provisional Agenda CBD/SBSTTA/24/3, United Nations Environment Program (UNEP). Available online at: https://www.cbd.int/doc/c/705d/6b4b/ala463clb19392bde6fa08f3/ sbstta-24-03-en.pdf (accessed May 20, 2021).

Utermöhl, H. (1958). Zur vervollkommnung der quantitativen phytoplanktonmethodik: mit 1 tabelle und 15 abbildungen im text und auf 1 tafel. Int. Vereinigung Theor. Angew. Limnol. 9, 1-38. doi: 10.1080/05384680.1958. 11904091

Vihervaara, P., Auvinen, A.-P., Mononen, L., Torma, M., Ahlroth, P., Anttila, S., et al. (2017). How essential biodiversity variables and remote sensing can help national biodiversity monitoring. Glob. Ecol. Conserv. 10, 43-59. doi: 10.1016/j. gecco.2017.01.007

Watkins, A. (2012). Biodiversity Interoperability Through Open Geospatial Standards. New Zealand Environmental Information Interoperability Framework. Available online at: https://teamwork.niwa.co.nz/display/ NZEIIF/Biodiversity+Interoperability+through+Open+Geospatial+Standards (accessed August 2, 2021).

White, R. L., Sutton, A. E., Salguero-Gomez, R., Bray, T. C., Campbell, H., Cieraad, E., et al. (2015). The next generation of action ecology: novel approaches towards global ecological research. Ecosphere 6, 1-16. doi: 10.1890/ES14-00485.1
Wilkinson, M. D., Dumontier, M., Aalbersberg, I. J., Appleton, G., Axton, M., Baak, A., et al. (2016). Comment: the FAIR guiding principles for scientific data management and stewardship. Sci. Data 3:160018. doi: 10.1038/sdata.2016.18

Wohner, C., Peterseil, J., Genazzio, M. A., Guru, S., Hugo, W., and Klug, H. (2020). Towards in-teroperable research site documentation - recommendations for information models and data provi-sion. Ecol. Inform. 60:101158. doi: 10.1016/j.ecoinf.2020.101158

Wohner, C., Peterseil, J., Poursanidis, D., Kliment, T., Wilson, M., Mirtl, M., et al. (2019). DEIMS-SDR - a web portal to document research sites and their associated data. Ecol. Inform. 51, 15-24. doi: 10.1016/j.ecoinf.2019.01.005

Xu, H., Cao, Y., Yu, D., Cao, M., He, Y., Gill, M., et al. (2021). Ensuring effective implementation of the post-2020 global biodiversity targets. Nat. Ecol. Evol. 5, 411-418. doi: 10.1038/s41559-02001375-y

Zilioli, M., Oggioni, A., Tagliolato, P., Pugnetti, A., and Carrara, P. (2019). Feeding essential biodiversity variables (EBVs): actual and potential contributions from LTER-Italy. Nat. Conserv. 477-503. doi: 10.3897/natureconservation.34.30735

Conflict of Interest: The authors declare that the research was conducted in the absence of any commercial or financial relationships that could be construed as a potential conflict of interest.

Publisher's Note: All claims expressed in this article are solely those of the authors and do not necessarily represent those of their affiliated organizations, or those of the publisher, the editors and the reviewers. Any product that may be evaluated in this article, or claim that may be made by its manufacturer, is not guaranteed or endorsed by the publisher.

Copyright (c) 2021 Zilioli, Bergami, Carrara, Fugazza, Oggioni, Pugnetti and Tagliolato Acquaviva d'Aragona. This is an open-access article distributed under the terms of the Creative Commons Attribution License (CC BY). The use, distribution or reproduction in other forums is permitted, provided the original author(s) and the copyright owner(s) are credited and that the original publication in this journal is cited, in accordance with accepted academic practice. No use, distribution or reproduction is permitted which does not comply with these terms. 